\title{
Dendrobium moniliforme Stem Extract Inhibits Lipoteichoic Acid-Induced Inflammatory Responses by Upregulation of Heme Oxygenase-1
}

\author{
Young Ji Lee ${ }^{1 \dagger}$, Ji-Hee Kim ${ }^{2 \dagger}$, and YoungHee Kim ${ }^{1,2 *}$ \\ ${ }^{1}$ Department of Molecular Biology, College of Natural Sciences, Pusan National University, Busan 46241, Republic of Korea \\ ${ }^{2}$ BK21Plus Research Group for Longevity and Marine Biotechnology, Pusan National University, Busan 46241, Republic of Korea
}

\author{
Received: July 13, 2018 \\ Revised: July 23, 2018 \\ Accepted: July 24, 2018 \\ First published online \\ July 31, 2018 \\ *Corresponding author \\ Phone: +82-51-510-2526; \\ Fax: +82-51-513-9258; \\ E-mail: yheekim@pusan.ac.kr \\ ${ }^{+}$These authors contributed \\ equally to this work. \\ pISSN 1017-7825, eISSN 1738-8872 \\ Copyright(C) 2018 by \\ The Korean Society for Microbiology \\ and Biotechnology
}

\begin{abstract}
The stems of Dendrobium moniliforme have been used in traditional herbal medicine for the treatment of fever and lack of body fluid in Korea. In this study, we investigated antiinflammatory effects of the aqueous extract of D. moniliforme stems (DM) in response to lipoteichoic acid (LTA), a major constituent of the cell wall of Gram-positive bacteria. DM inhibited LTA-induced expression of a pro-inflammatory mediator inducible nitric oxide synthase (iNOS) in the murine macrophages. And DM induced expression of heme oxygenase-1 (HO-1) at the transcriptional level. Conversely, the knockdown of HO-1 expression by siRNA markedly reversed the inhibitory effects of DM on LTA-induced iNOS expression. We also demonstrated that nuclear translocation of Nrf2 was increased following treatment with DM. In addition, DM-mediated Nrf2 activation and HO-1 expression were suppressed by PI3K/Akt and p38 inhibitors; treatment with DM also resulted in phosphorylation of Akt and p38. These results suggest that DM inhibits the expression of iNOS in LTA-stimulated macrophages, and that these effects are mediated by the upregulation of HO-1 expression via PI3K/Akt/p38-Nrf2 signaling.
\end{abstract}

Keywords: Dendrobium moniliforme, heme oxygenase-1 (HO-1), inducible nitric oxide synthase (iNOS), lipoteichoic acid, NF-E2-related factor 2 (Nrf2)

\section{Introduction}

Lipoteichoic acid (LTA) is a major component of the cell wall of Gram-positive bacteria including Staphylococcus aureus, a common cause of abscesses, sinusitis, food poisoning, and wound infections following surgery. LTA plays an important role in a number of infectious diseases including skin infections [1], pneumonia [2], meningitis [3], and sepsis [4], and has led to high mortality [5]. LTA is a pathogen-associated molecular pattern (PAMP) molecule in Gram-positive pathogenic bacteria and may bind to Tolllike receptors-2 (TLR-2) [6, 7]. Signal transduction via TLR2 activates nuclear factor-kappaB (NF- $\kappa \mathrm{B})$, leading to the expression of pro-inflammatory molecules such as inducible nitric oxide synthase (iNOS), cytokines, and chemokines. A large amount of nitric oxide (NO) synthesized by iNOS has been implicated in the pathogenesis of various inflammatory disease [8]. Thus inhibition of NO production has been suggested as an effective strategy for the treatment of inflammatory diseases.

Heme oxygenase-1 (HO-1) is an inducible enzyme that mediates the degradation of cellular heme into carbon monoxide (CO), free iron, and biliverdin, which is further converted to bilirubin by biliverdin reductase [9]. HO-1 end-products $\mathrm{CO}$ and biliverdin are thought to have antiapoptotic and anti-inflammatory functions, and increased intracellular levels of iron up-regulate ferritin, an ironstoring protein that participates in the cytoprotective machinery $[9,10]$. Growing evidences have demonstrated that many compounds induce $\mathrm{HO}-1$ expression and exhibit their anti-inflammatory effects via HO-1 up-regulation [10-16]. Furthermore, human and murine HO-1 deficiency exhibit increased oxidative stress, persistent vascular injury, and chronic inflammation $[17,18]$.

NF-E2-related factor 2 (Nrf2) is known to be major transcription factor which regulates HO-1 expression [19]. In basal conditions, Nrf2 is present in the cytoplasm bound to Kelch-like ECH-associated protein 1 (Keap1), and degraded 
by the ubiquitin-dependent $26 \mathrm{~S}$ proteasome system [20]. During activation, Nrf2 is released from inhibition by Keap1, translocates to the nucleus, heterodimerizes with Maf, and binds to antioxidant response elements (AREs) located in the promoter regions of many detoxifying/ antioxidant genes, including HO-1 [20, 21].

The stems of Dendrobium moniliforme (L.) Sw have been used in traditional Chinese and Korean medicine as a Yin tonic to nourish the stomach, promote the production of body fluid, and reduce fever [22, 23]. D. moniliforme is known to produce a variety of secondary metabolites, such as alkaloids [24], sesquiterpenes [25, 26], and phenanthrenes $[27,28]$. Several biological activities have been reported for D. moniliforme, such as free radical scavenging [23, 29], immunoregulatory [25], anti-inflammatory [27, 30], and anti-tumor [28] activities, as well as reno-protective effects in high fat diet-treated mice [31]. We previously examined that $D$. moniliforme inhibits lipopolysaccharide-stimulated production of NO and IL-1 $\beta$ in macrophages [30]. However, the mechanism responsible for its anti-inflammatory actions has not been fully understood. In this study, we investigated the effects of the aqueous extract of D. moniliforme (DM) stem on the LTA-induced inflammatory response in macrophages. Our finding is the first report clarifying D. moniliforme exhibits anti-inflammatory effects via upregulation of HO-1.

\section{Materials and Methods}

\section{Materials and Preparation of Extract}

Cobalt protoporphyrin (CoPP) was purchased from Enzo Life Sciences, Inc. (USA). Actinomycin D (AD), cycloheximide (CHX), 3-(4,5-dimethylthiazol-2-yl)-2,5-diphenyltetrazolium bromide (MTT), and LTA from Staphylococcus aureus were purchased from SigmaAldrich Co. (USA). LY294002, PD98059, SP600125 and SB203580 were obtained from A.G. Scientific (USA). The antibodies for iNOS, HO-1, Nrf2, Akt, p38, TATA-box binding protein (TBP) and histone deacetylases (HDAC) were purchased from Santa Cruz Biotechnology (USA), the antibodies for phospho-Akt and phospho-p-38 were purchased from Cell Signaling Technology (USA), and the anti-tubulin antibody was purchased from Bio Genex (USA). The dry shoot systems of D. moniliforme Sw. were obtained and extracted as described previously [30]. In brief, the dry shoot systems $(300 \mathrm{~g})$ were extracted with distilled water at $100^{\circ} \mathrm{C}$ for $4 \mathrm{~h}$. The extract was filtered through a $0.45-\mu \mathrm{m}$ filter, freeze-dried (yield: $8 \mathrm{~g}$ ), and stored at $4^{\circ} \mathrm{C}$. The dried extract was dissolved in phosphate-buffered saline (PBS) and filtered through a $0.22 \mu \mathrm{m}$-filter before use.

\section{Cell Culture}

Murine macrophage RAW 264.7 cells were maintained in Dulbecco's modified Eagle's medium supplemented with glutamine
$(1 \mathrm{mM})$ and $10 \% \mathrm{FBS}$ at $37^{\circ} \mathrm{C}$ in an atmosphere of $5 \% \mathrm{CO}_{2}$.

\section{Measurement of Nitrite Concentration}

NO production in cell culture was measured by a microplate assay method as described previously [15].

\section{Cell Viability Assay}

The cytotoxicity of DM was estimated using a microculture MTT-based colorimetric assay as described previously [15].

\section{Western Blot Analysis}

Cytosolic and nuclear proteins were extracted as described previously [32]. Western blotting was performed as described previously [16]. Tubulin or TATA binding protein (TBP) were used as protein-loading controls for each lane. Quantitative image analysis was performed using image analysis software, ImageJ (http:// rsb.info.nih.gov/ij) and data were presented as fold of control.

\section{Reverse Transcription (RT)-Polymerase Chain Reaction (PCR)}

The total cellular RNA was isolated using RNA-spin mini RNA isolation kits (GE Healthcare, USA) in accordance with the manufacturer's instructions. Total RNA $(1 \mu \mathrm{g})$ was reversetranscribed using Maxime RT PreMix (Intron Biotechnology, Korea) with oligo-dT15-primers. PCR was performed in a TaKaRa PCR Thermal Cycler Dice (TaKaRa Bio Inc., Japan). The primer sequences were as follows: HO-1-sense (5'-GTTGACGGACCC CAAAAGAT-3'), HO-1-antisense (5'-CCTCATCCTGGAAGGTCC AC-3'), GAPDH-sense (5'-AGGTGGTCTCCTCTGACTTC-3'), and GAPDH-antisense (5'-TACCAGGAAATGAGCTTGAC-3').

\section{Immunofluorescence Confocal Microscopy}

Immunofluorescence confocal microscopy was performed as described previously [16].

\section{Interference of HO-1}

The siRNAs for HO-1 (GenBank Accession No. NM 010442.1) were synthesized by Bioneer (Korea). The cells were transfected with HO-1 siRNA or negative control siRNA using INTERFERin (Polyplus transfection, Illkirch, France) and then incubated for $48 \mathrm{~h}$ until the protein expression was detected.

\section{Statistical Analysis}

All results were expressed as the mean $\pm \mathrm{SE}$ (standard error). Each experiment was repeated at least three times. Statistical analysis was performed by using SPSS software to determine significant differences. We used one-way analysis of variance (ANOVA) followed by Tukey's post hoc test for comparison of three or more groups. A value of $p<0.05$ was considered statistically significant.

\section{Results}

\section{DM Inhibits iNOS Expression in Macrophages}

To investigate the anti-inflammatory effect of DM, we 
A

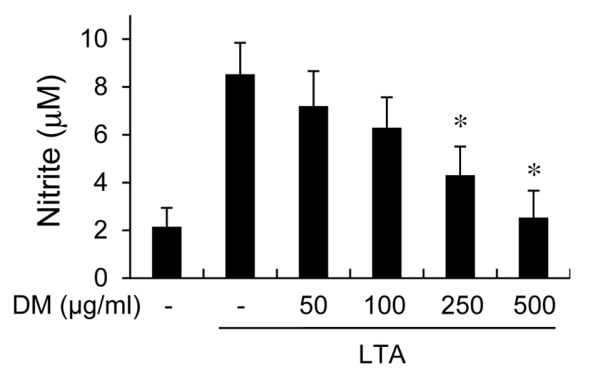

B

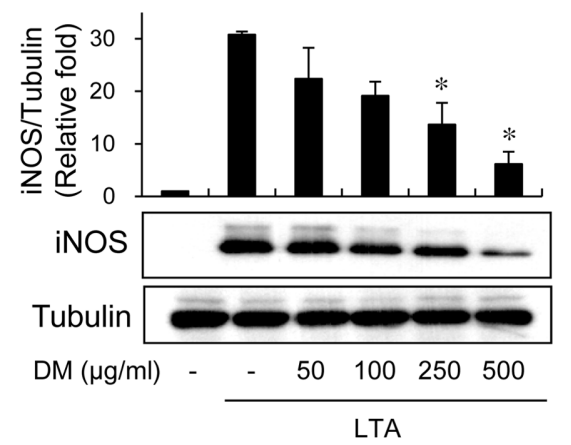

C

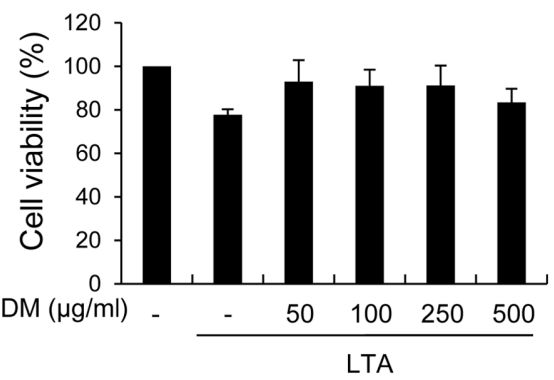

Fig. 1. Effect of DM on the production of NO in macrophages.

(A) RAW 264.7 cells were incubated with various concentrations of DM for $1 \mathrm{~h}$ and then stimulated with LTA (10 $\mu \mathrm{g} / \mathrm{ml})$ for $20 \mathrm{~h}$. The production of NO was measured via Griess test. (B) Cells were treated as mentioned above, and then expression of iNOS was analyzed via Western blot and analyzed according to the Materials and methods. (C) Cell viability was measured via MTT assay. ${ }^{*} p<0.05$ vs. LTA-treated group.

first examined the effect of DM on NO synthesis in murine macrophage RAW 264.7 cells. Pretreatment of DM suppressed LTA-induced NO release in a dose-dependent manner (Fig. 1A). Additionally, the expression level of iNOS was significantly decreased by DM in a dose-dependent manner

A

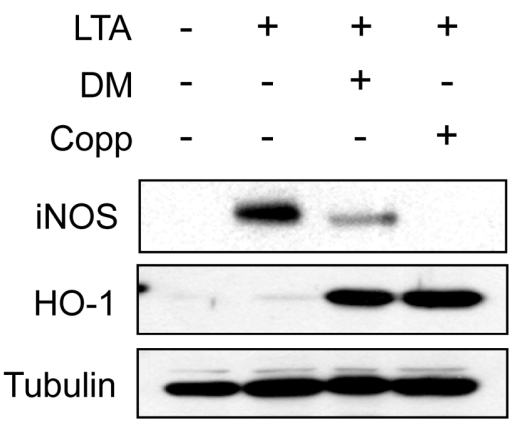

C

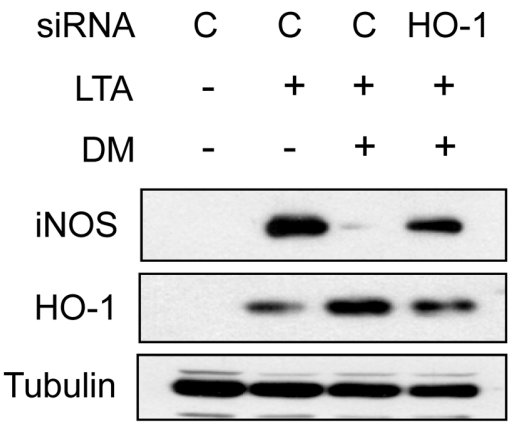

in Western blot analysis (Fig. 1B). On the other hand, DM did not influence the cell viability as measured via MTT assay (Fig. 1C). These results suggest that DM inhibits iNOS expression and NO production without affecting cell viability.
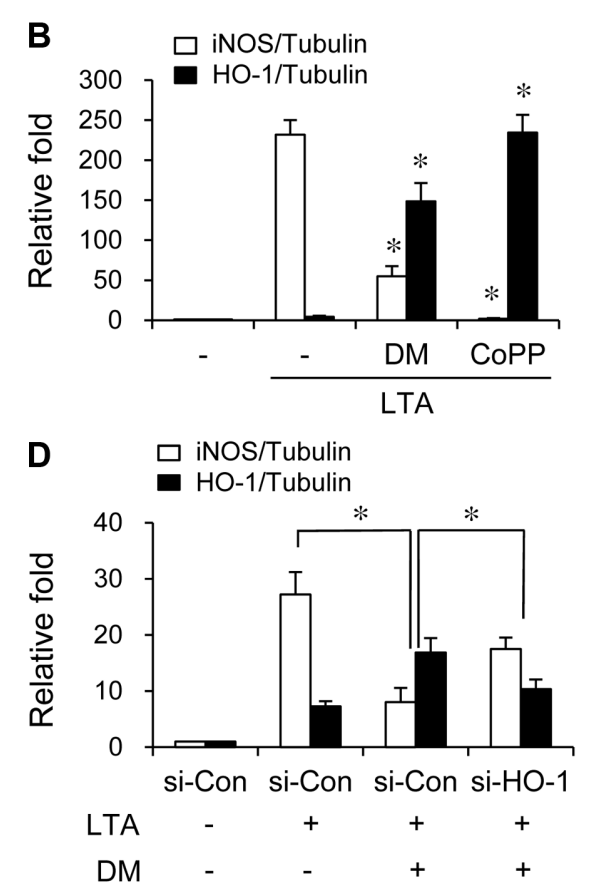

Fig. 2. Inhibitory effect of HO-1 on iNOS expression.

(A) Cells were incubated with DM $(500 \mu \mathrm{g} / \mathrm{ml})$ or CoPP $(10 \mu \mathrm{M})$ for $1 \mathrm{~h}$ and then stimulated with LTA $(10 \mu \mathrm{g} / \mathrm{ml})$ for $20 \mathrm{~h}$. Protein levels of iNOS and HO-1 were analyzed via Western blot. (B) Protein expression was relatively quantified according to the Materials and methods. ${ }^{*} p<0.05$ vs. LTA-treated group. (C) Cells were transfected with HO-1 siRNA or control siRNA, pretreated with DM (500 $\mu \mathrm{g} / \mathrm{ml})$ for $1 \mathrm{~h}$ and then stimulated with LTA $(10 \mu \mathrm{g} / \mathrm{ml})$ for $20 \mathrm{~h}$. Protein levels of iNOS and HO-1 were analyzed via Western blot. (D) Protein expression was relatively quantified. si-Con and si-HO-1represents control siRNA and HO-1 siRNA, respectively. ${ }^{*} p<0.05$ for each group (both of iNOS and HO-1). 


\section{DM Exhibits Anti-Inflammatory Effects Via Induction of HO-1}

To examine whether HO-1 suppresses the expression of iNOS, cells were pretreated with CoPP, an inducer of HO-1, and incubated with LTA for $20 \mathrm{~h}$. As shown in Figs. 2A and 2B, CoPP treatment significantly inhibited the expression of iNOS in parallel with $\mathrm{HO}-1$ induction, and DM treatment also showed similar effects. To confirm DM exhibits its anti-inflammatory effect via the induction of HO-1 expression, we used an HO-1 small interfering (si) RNA system. Decreased HO-1 expression by HO-1 si-RNA blocked DM-mediated inhibition of LTA-stimulated iNOS expression, whereas control siRNA showed no effect (Figs. 2C and 2D).

\section{DM Induces HO-1 Expression in Murine Macrophages}

Next, we examined the expression of HO-1 by DM in macrophages. DM dramatically increased $\mathrm{HO}-1$ protein and mRNA levels in a dose-dependent manner (Figs. 3A3C). CoPP was used as a positive control. To verify that DM-induced HO-1 expression is mediated by transcription and translation, we used AD to inhibit DNA-dependent RNA polymerase, and CHX to inhibit ribosomal protein synthesis. AD or CHX significantly decreased DM-induced HO-1 expression (Figs. 3D and 3E). Taken together, these results indicate that $\mathrm{DM}$ induces $\mathrm{HO}-1$ expression at the transcriptional level.

\section{DM-Induced HO-1 Expression Is Mediated by Nrf2}

Since the expression of $\mathrm{HO}-1$ is known to be regulated by Nrf2 [19], we investigated whether DM activates Nrf2 in RAW 264.7 cells. Nuclear levels of Nrf2, which are critical to its transcriptional activity, were examined via Western blotting and immunofluorescence confocal microscopy. As shown in Fig. 4, DM significantly increased nuclear level of Nrf2 in a dose-dependent manner. These results suggest that DM activates Nrf2, which in turn induces $\mathrm{HO}-1$ expression.

\section{DM Mediates HO-1 Expression through PI3K/Akt and p38 Kinase}

To investigate what signaling pathway is involved in DM-mediated Nrf2 activation and HO-1 expression, we used pharmacological inhibitors of PI3K and MAPKs (PI3K/Akt: LY294002, ERK: PD98059, JNK: SP600125, and p38: SB203580). Pre-treatment of RAW 264.7 cells with

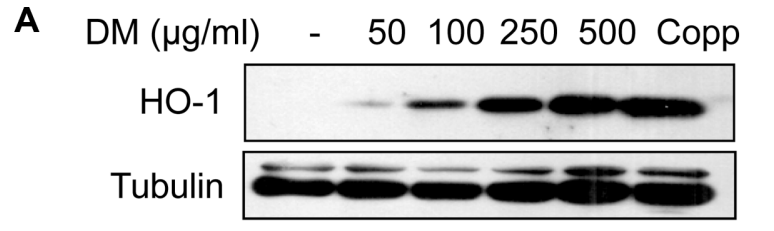

C $\mathrm{DM}(\mu \mathrm{g} / \mathrm{ml}) \quad-\quad 50100250500$ Copp

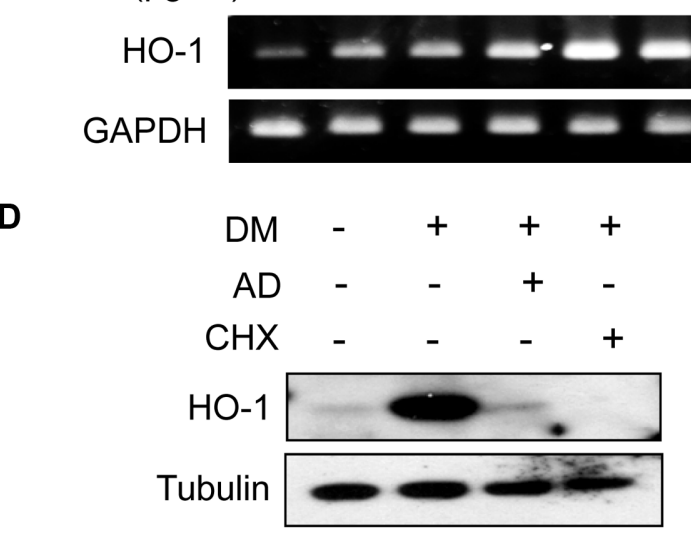

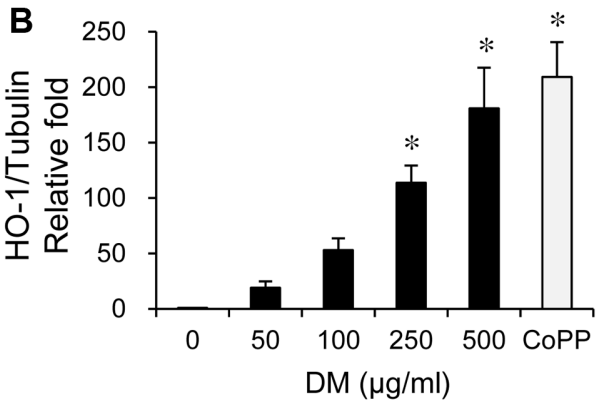

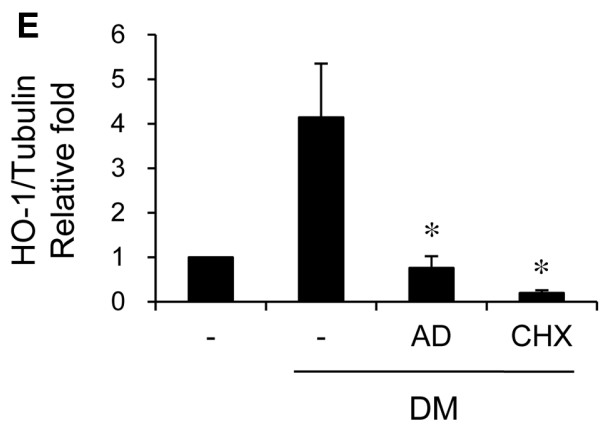

Fig. 3. Induction of HO-1 by DM.

(A) Cells were incubated with various concentrations of DM or CoPP $(10 \mu \mathrm{M})$ for $8 \mathrm{~h}$, and HO-1 protein levels were analyzed via Western blot. (B) Protein expression was relatively quantified. ${ }^{*} p<0.05$ vs. control group. (C) Cells were treated as mentioned above and mRNA levels were analyzed via RT-PCR. (D) Cells were treated with DM $(500 \mu \mathrm{g} / \mathrm{ml})$ for $8 \mathrm{~h}$ in the absence or presence of AD $(1 \mu \mathrm{g} / \mathrm{ml})$ or CHX $(1 \mu \mathrm{g} / \mathrm{ml})$. Protein levels of HO-1 were analyzed via Western blot. (E) Protein expression was relatively quantified. ${ }^{*} p<0.05$ vs. DM-treated group. 

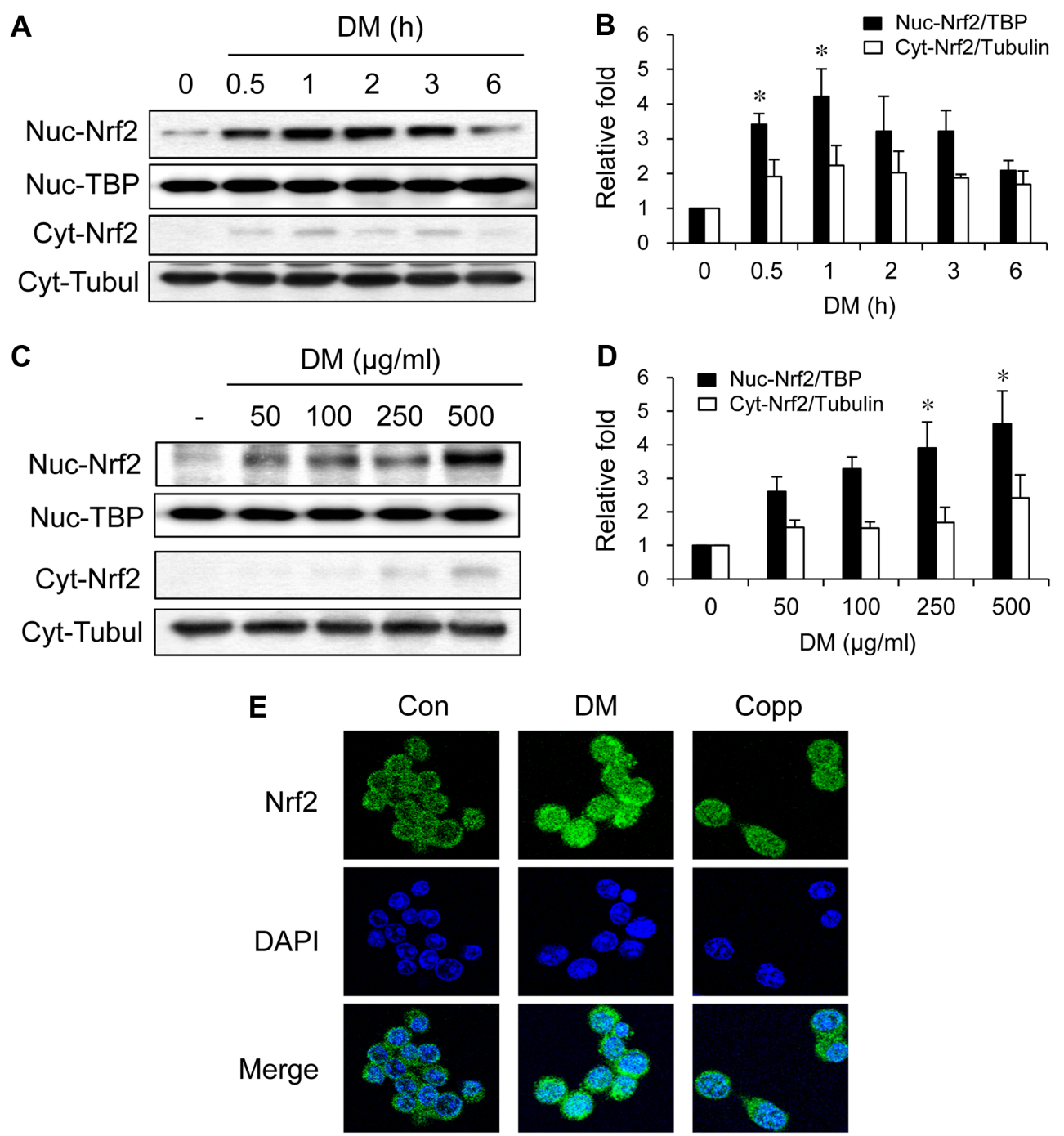

Fig. 4. Effect of DM on Nrf2 activation.

Cells were incubated with DM (500 $\mu \mathrm{g} / \mathrm{ml})$ for indicated times (A), or indicated concentrations of DM for $1 \mathrm{~h}(\mathrm{C})$. Nuclear Nrf2 and TBP (NucNrf2 and Nuc-TBP) and cytosolic Nrf2 and tubulin (Cyt-Nrf2 and Cyt-Tubul) were assayed via Western blot, and relative expression of Nrf2 was analyzed (B and D). ${ }^{*} p<0.05$ vs. control group. (E) Cells were incubated with DM ( $\left.500 \mu \mathrm{g} / \mathrm{ml}\right)$ for $1 \mathrm{~h}$ on coverslips in $35 \mathrm{~mm}$ dishes, and nuclear accumulation of Nrf2 was confirmed via confocal microscopy.

LY294002 or SB203580 inhibited DM-induced HO-1 expression and Nrf2 nuclear accumulation (Figs. 5A and 5B). In addition, treatment of RAW 264.7 cells with DM increased phosphorylation of Akt and p38 kinase (Figs. 5C and 5D). These results suggest that DM increases Nrf2 activation and HO-1 expression via PI3K/Akt and p38 kinase signaling pathways.

\section{Discussion}

In the present study, we examined the effects of DM on
LTA-induced inflammation in vitro, and the relationship between HO-1 expression and the inhibition of LTAinduced inflammation. We found that DM inhibited the production of NO and suppressed the expression of iNOS in the murine macrophages (Fig. 1). Excessive production of NO by iNOS in macrophages is believed to play a critical role in the pathogenesis of various inflammation-related diseases. Thus suppression of iNOS expression in macrophages could represent an attractive target to treat various inflammatory diseases [33-37]. Thus our results suggest that DM could be a useful remedial agent for Gram- 
A

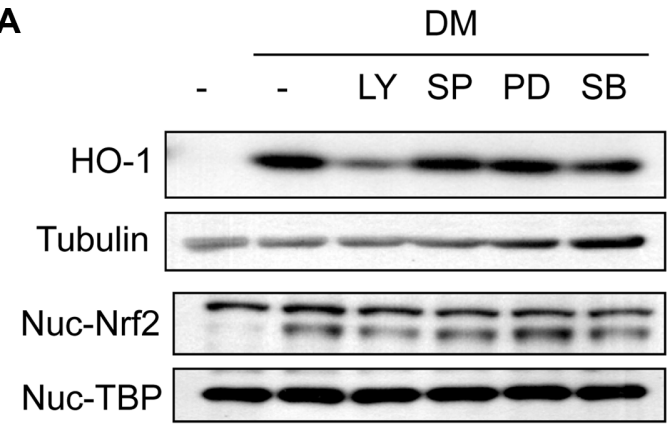

C

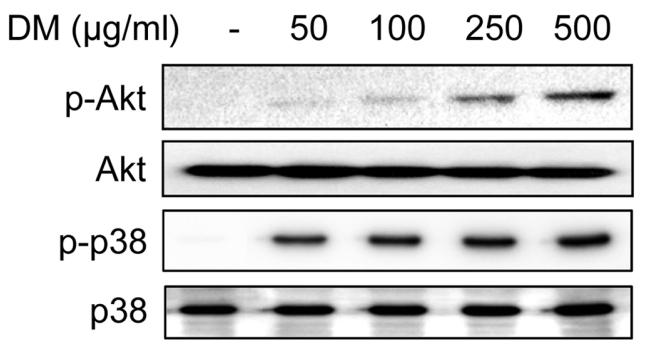

B

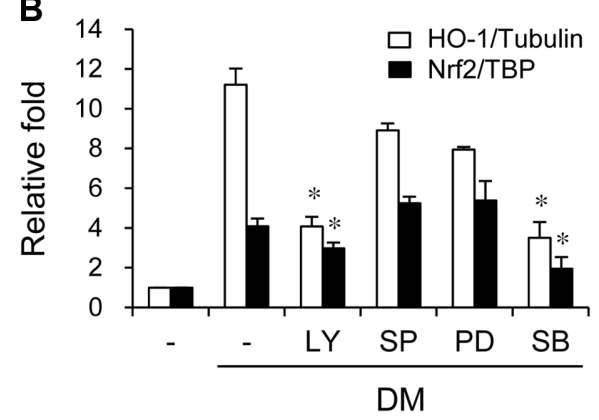

D

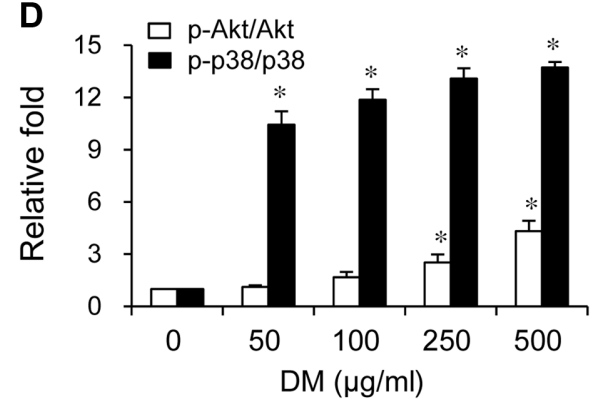

Fig. 5. Involvement of Akt and p38 kinase in DM-mediated expression of HO-1.

(A) Cells were incubated with LY294002 (LY, $10 \mu \mathrm{M}$ ), SP600125 (SP, $20 \mu \mathrm{M})$, PD98059 (PD, $20 \mu \mathrm{M}$ ), and SB203580 (SB, $20 \mu \mathrm{M})$ for 30 min and then treated with DM $(500 \mu \mathrm{g} / \mathrm{ml})$ for $8 \mathrm{~h}$ for HO-1 or $1 \mathrm{~h}$ for Nrf2. Equal amounts of cytosolic (for HO-1) or nuclear (for Nrf2) extract were analyzed via Western blot. (B) Protein expression was relatively quantified. ${ }^{*} p<0.05$ vs. DM-treated group. (C) Cells were incubated with various concentrations of DM for $30 \mathrm{~min}$ and equal amounts of cytosolic extract were analyzed via Western blot. (D) Protein expression was relatively quantified. ${ }^{*} p<0.05$ vs. control group.

positive bacteria-mediated inflammatory diseases such as skin infections, pneumonia, meningitis, and sepsis.

HO-1 is known to exhibit anti-inflammatory activities by inhibiting production of pro-inflammatory mediators [11, 12, 38], suggesting a potential therapeutic strategy for treating inflammatory diseases. We found that DM markedly induced HO-1 expression at the transcriptional level (Fig. 3). Because HO-1 is known to be induced by chemicalmediated oxidative stress [39], we examined whether DM increased HO-1 expression by inducing cell damage. A cell viability assay (MTT assay) revealed that DM does not affect cell viability (Fig. 1C), suggesting that HO-1 is specifically induced by DM, not by cell damage. Moreover, the reduction of HO-1 expression via siRNA significantly repealed the inhibitory effects of DM on LTA-induced iNOS expression, while treatment with CoPP suppressed iNOS expression (Fig. 2). These data suggest that DM inhibit iNOS expression via HO-1 induction. Although the effect of HO-1 end-products was not examined in this study, several studies indicate $\mathrm{CO}$ and biliverdin could play a role to ameliorate inflammation [40, 41].

This study showed that DM increased nuclear accumulation of Nrf2 in a dose-dependent manner (Fig. 4), suggesting that DM activates Nrf2 translocation into the nucleus, which gives rise to induction of HO-1 expression. Because Nrf2 regulates HO-1 as well as other detoxifying and antioxidant proteins including $\mathrm{NAD}(\mathrm{P}) \mathrm{H}$ quinone oxidoreductase 1 (NQO-1), thioredoxin-1 (Trx1) and glutathione S-transferase (GST) [42], it is possible that DM may upregulate NQO-1, Trx1 and/or GST, although this was not examined in our study. Several studies demonstrated that PI3K and MAPKs such as ERK, JNK, and p38 are involved in Nrf2 and HO-1 signaling in response to various stimuli [14, 43]. However, these signaling pathways depend on the type of cells and stimuli in terms of their contribution to HO-1 expression. This study showed that DM-mediated Nrf2 activation and HO-1 expression were regulated by PI3k/Akt and p38 (Fig. 5). Recently, Sun et al. [44] described that Nrf2 is phosphorylated at multiple sites by MAPK to facilitate its nuclear translocation. Thus it is possible that DM-induced PI3K/Akt and p38 activities directly phosphorylate Nrf2 and promote nuclear translocation of Nrf2, even if phosphorylation of Nrf2 was not examined in this study. Naturally, the possibility that PI3K/Akt and p38 regulate 
the Nrf2 activity through indirect mechanisms should not rule out.

In conclusion, we demonstrated that DM inhibits the expression of iNOS in LTA-stimulated macrophages in vitro, and that this effect is mediated by upregulation of HO-1 expression via PI3K/Akt/p38-Nrf2 signaling. Our findings could help us understand the molecular mechanism of the anti-inflammatory actions of DM.

\section{Conflict of Interest}

The authors have no financial conflicts of interest to declare.

\section{Acknowledgments}

This work was supported by the Financial Supporting Project of Long-term Overseas Dispatch of PNU's Tenuretrack Faculty, 2014, and the Research Fund Program of Research Institute for Basic Sciences, Pusan National University, Korea, 2012, Project No. RIBS-PNU-2012-105.

\section{References}

1. Baroni A, Perfetto B, Ruocco E, Rossano F. 1998. Lipoteichoic acid and protein-A from Staphylococcus aureus stimulate release of hepatocyte growth factor (HGF) by human dermal fibroblasts. Arch. Dermatol. Res. 290: 211-214.

2. Wu BQ, Luo JM, Wang YH, Shi YF, Liu H, Ba JH, et al. 2014. Inhibitory effects of simvastatin on Staphylococcus aureus lipoteichoic acid-induced inflammation in human alveolar macrophages. Clin. Exp. Med. 14: 151-160.

3. Sheen TR, Ebrahimi CM, Hiemstra IH, Barlow SB, Peschel A, Doran KS. 2010. Penetration of the blood-brain barrier by Staphylococcus aureus: contribution of membrane-anchored lipoteichoic acid. J. Mol. Med. 88: 633-639.

4. De Kimpe SJ, Kengatharan M, Thiemermann C, Vane JR. 1995. The cell wall components peptidoglycan and lipoteichoic acid from Staphylococcus aureus act in synergy to cause shock and multiple organ failure. Proc. Natl. Acad. Sci. USA 92: 10359-10363.

5. Ginsburg I. 2002. Role of lipoteichoic acid in infection and inflammation. Lancet Infect. Dis. 2: 171-179.

6. Kang SS, Sim JR, Yun CH, Han SH. 2016. Lipoteichoic acids as a major virulence factor causing inflammatory responses via Toll-like receptor 2. Arch. Pharm. Res. 39: 1519-1529.

7. Hong SW, Baik JE, Kang SS, Yun CH, Seo DG, Han SH. 2014. Lipoteichoic acid of Streptococcus mutans interacts with Toll-like receptor 2 through the lipid moiety for induction of inflammatory mediators in murine macrophages. Mol. Immunol. 57: 284-291.
8. Southan GJ, Szabo C. 1996. Selective pharmacological inhibition of distinct nitric oxide synthase isoforms. Biochem. Pharmacol. 51: 383-394.

9. Ryter SW, Alam J, Choi AM. 2006. Heme oxygenase-1/carbon monoxide: from basic science to therapeutic applications. Physiol. Rev. 86: 583-650.

10. Otterbein LE, Bach FH, Alam J, Soares M, Tao Lu H, Wysk M, et al. 2000. Carbon monoxide has anti-inflammatory effects involving the mitogen-activated protein kinase pathway. Nat. Med. 6: 422-428.

11. Motterlini R, Foresti R. 2014. Heme oxygenase-1 as a target for drug discovery. Antioxid. Redox Signal. 20: 1810-1826.

12. Ryter SW, Choi AM. 2016. Targeting heme oxygenase-1 and carbon monoxide for therapeutic modulation of inflammation. Transl. Res. 167: 7-34.

13. Suh GY, Jin Y, Yi AK, Wang XM, Choi AM. 2006. CCAAT/ enhancer-binding protein mediates carbon monoxide-induced suppression of cyclooxygenase-2. Am. J. Respir. Cell Mol. Biol. 35: 220-226.

14. Kim JH, Park GY, Bang SY, Park SY, Bae SK, Kim Y. 2014. Crocin suppresses LPS-stimulated expression of inducible nitric oxide synthase by upregulation of heme oxygenase-1 via calcium/calmodulin-dependent protein kinase 4. Mediators Inflamm. 2014: 728-709.

15. Park SY, Kim JH, Lee SJ, Kim Y. 2013. Involvement of PKA and HO-1 signaling in anti-inflammatory effects of surfactin in BV-2 microglial cells. Toxicol. Appl. Pharmacol. 268: 68-78.

16. Bang SY, Kim J-H, Kim H-Y, Lee YJ, Park SY, Lee SJ, et al. 2012. Achyranthes japonica exhibits anti-inflammatory effect via NF-kB suppression and HO-1 induction in macrophages. J. Ethnopharmacol. 144: 109-117.

17. Poss KD, Tonegawa S. 1997. Reduced stress defense in heme oxygenase 1-deficient cells. Proc. Natl. Acad. Sci. USA 94: 10925-10930.

18. Yachie A, Niida Y, Wada T, Igarashi N, Kaneda H, Toma T, et al. 1999. Oxidative stress causes enhanced endothelial cell injury in human heme oxygenase-1 deficiency. J. Clin. Invest. 103: 129-135.

19. Srisook K, Kim C, Cha YN. 2005. Molecular mechanisms involved in enhancing HO-1 expression: de-repression by heme and activation by Nrf2, the "one-two" punch. Antioxid Redox Signal. 7: 1674-1687.

20. Itoh K, Mimura J, Yamamoto M. 2010. Discovery of the negative regulator of Nrf2, Keap1: a historical overview. Antioxid. Redox Signal. 13: 1665-1678.

21. Motohashi H, Katsuoka F, Engel JD, Yamamoto M. 2004. Small Maf proteins serve as transcriptional cofactors for keratinocyte differentiation in the Keap1-Nrf2 regulatory pathway. Proc. Natl. Acad. Sci. USA 101: 6379-6384.

22. Ahn DK. 2003. Illustrated book of Korean medicinal herbs, pp. 707. Kyohak Publishing Co., Seoul, Korea

23. Lo SF, Mulabagal V, Chen CL, Kuo CL, Tsay HS. 2004. Bioguided fractionation and isolation of free radical scavenging 
components from in vitro propagated Chinese medicinal plants Dendrobium tosaense Makino and Dendrobium moniliforme SW. J. Agric. Food Chem. 52: 6916-6919.

24. Chen YL, Zhang M, Hua YF, He GQ. 2001. Studies on polysaccharide alkaloids and minerals from Dendrobium moniliforme (L.) Sw. China J. Chin. Materia Medica. 26: 709-710.

25. Zhao C, Liu Q, Halaweish F, Shao B, Ye Y, Zhao W. 2003. Copacamphane, picrotoxane, and alloaromadendrane sesquiterpene glycosides and phenolic glycosides from Dendrobium moniliforme. J. Nat. Prod. 66: 1140-1143.

26. Zhao W, Ye Q, Dai J, Martin MT, Zhu J. 2003. Alloaromadendrane- and picrotoxane-type sesquiterpenes from Dendrobium moniliforme. Planta Med. 69: 1136-1140.

27. Lin TH, Chang SJ, Chen CC, Wang JP, Tsao LT. 2001. Two phenanthraquinones from Dendrobium moniliforme. J. Nat. Prod. 64: 1084-1086.

28. Sanchez-Duffhues G, Calzado MA, de Vinuesa AG, Appendino G, Fiebich BL, Loock U, et al. 2009. Denbinobin inhibits nuclear factor-kappaB and induces apoptosis via reactive oxygen species generation in human leukemic cells. Biochem. Pharmacol. 77: 1401-1409.

29. Ohsugi M, Fan W, Hase K, Xiong Q, Tezuka Y, Komatsu K, et al. 1999. Active-oxygen scavenging activity of traditional nourishing-tonic herbal medicines and active constituents of Rhodiola sacra. J. Ethnopharmacol. 67: 111-119.

30. Park GY, Bae CH, Park SY, Kim JH, Ko WS, Kim Y. 2009. Inhibitory effect of Dendrobium moniliforme on NO and IL-1 $\beta$ production in LPS-stimulated macrophages. J. Kor. Med. Ophthalmol. Otolaryngol. Dermatol. 22: 11-19.

31. Lee W, Eom D-W, Jung Y, Yamabe N, Lee S, Jeon Y, et al. 2012. Dendrobium moniliforme attenuates high-fat diet-induced renal damage in mice through the regulation of lipidinduced oxidative stress. Am. J. Chin. Med. 40: 1217-1228.

32. Andrews NC, Faller DV. 1991. A rapid micropreparation technique for extraction of DNA-binding proteins from limiting numbers of mammalian cells. Nucleic Acids Res. 19: 2499.

33. Naito $Y$, Takagi $T$, Ichikawa $H$, Tomatsuri N, Kuroda $M$, Isozaki $Y$, et al. 2004. A novel potent inhibitor of inducible nitric oxide inhibitor, ONO-1714, reduces intestinal ischemiareperfusion injury in rats. Nitric Oxide 10: 170-177.

34. Lee CY, Yang JJ, Lee SS, Chen CJ, Huang YC, Huang KH, et al. 2014. Protective effect of Ginkgo biloba leaves extract,
EGb761, on endotoxin-induced acute lung injury via a JNKand Akt-dependent NFkappaB pathway. J. Agric. Food Chem. 62: 6337-6344.

35. Gong X, Yang Y, Huang L, Zhang Q, Wan RZ, Zhang P, et al. 2017. Antioxidation, anti-inflammation and anti-apoptosis by paeonol in LPS/d-GalN-induced acute liver failure in mice. Int. Immunopharmacol. 46: 124-132.

36. Ishii $M$, Nakahara $T$, Araho D, Murakami J, Nishimura $M$. 2017. Glycolipids from spinach suppress LPS-induced vascular inflammation through eNOS and NK-kappaB signaling. Biomed. Pharmacother. 91: 111-120.

37. Jarvinen $K$, Vuolteenaho $K$, Nieminen $R$, Moilanen $T$, Knowles RG, Moilanen E. 2008. Selective iNOS inhibitor 1400W enhances anti-catabolic IL-10 and reduces destructive MMP-10 in OA cartilage. Survey of the effects of $1400 \mathrm{~W}$ on inflammatory mediators produced by OA cartilage as detected by protein antibody array. Clin. Exp. Rheumatol. 26: 275-282.

38. Cheng Y, Rong J. 2017. Therapeutic potential of heme oxygenase-1/carbon monoxide system against ischemiareperfusion injury. Curr. Pharm. Des. 23: 3884-3898.

39. Keyse SM, Tyrrell RM. 1989. Heme oxygenase is the major $32-\mathrm{kDa}$ stress protein induced in human skin fibroblasts by UVA radiation, hydrogen peroxide, and sodium arsenite. Proc. Natl. Acad. Sci. USA 86: 99-103.

40. Bonelli M, Savitskaya A, Steiner CW, Rath E, Bilban M, Wagner O, et al. 2012. Heme oxygenase-1 end-products carbon monoxide and biliverdin ameliorate murine collagen induced arthritis. Clin. Exp. Rheumatol. 30: 73-78.

41. Fagone P, Mangano K, Coco M, Perciavalle V, Garotta G, Romao CC, et al. 2012. Therapeutic potential of carbon monoxide in multiple sclerosis. Clin. Exp. Immunol. 167: 179-187.

42. Zhang M, An C, Gao Y, Leak RK, Chen J, Zhang F. 2013. Emerging roles of Nrf2 and phase II antioxidant enzymes in neuroprotection. Prog. Neurobiol. 100: 30-47.

43. Nemmiche S, Chabane-Sari D, Kadri M, Guiraud P. 2012. Cadmium-induced apoptosis in the BJAB human B cell line: involvement of PKC/ERK1/2/JNK signaling pathways in HO-1 expression. Toxicology 300: 103-111.

44. Sun Z, Huang Z, Zhang DD. 2009. Phosphorylation of Nrf2 at multiple sites by MAP kinases has a limited contribution in modulating the Nrf2-dependent antioxidant response. PLoS One 4: e6588. 